\title{
An Unusual Presentation of Pancreatic Cancer
}

\author{
Muzamil Latief', Waseem Raja Dar ${ }^{1, *}$, Ouber Qayoom ${ }^{1}$, Najeebullah Sofi $^{1}$, Imtiyaz Ahmad Dar ${ }^{1}$, Farhat Abbas ${ }^{1}$ and Pervez Sofi ${ }^{2}$ \\ ${ }^{1}$ Department of Medicine, Gastroenterology Division, Shere Kashmir Institute of Medical Sciences, Soura, Jammu and Kashmir, India \\ ${ }^{2}$ Department of Critical Care, Sanjeev Bansal Cygnus Hospital Haryana, India
}

\begin{abstract}
Pancreatic cancer is the fourth leading cause of cancer deaths, being responsible for $7 \%$ of all cancer-related deaths in both men and women. Patients usually present with weight loss, epigastric pain, obstructive jaundice or development of diabetes mellitus. Unusual presentations include pancreatic rupture, depression, icthyosis etc. Presentation as upper gastrointestinal bleed is very rare in pancreatic cancer and usually occurs due to sinistral portal hypertension. We present here a case of pancreatic cancer that presented to us as upper GI bleed.
\end{abstract}

\section{Introduction}

Pancreatic cancer is the fourth leading cause of cancer deaths, being notoriously difficult to diagnose in early stages. Approximately $75 \%$ of all pancreatic carcinomas occur within the head or neck of the pancreas, $15-20 \%$ occurs in the body of the pancreas, and 5-10\% occur in the tail. Patients usually present with advanced disease hence prognosis often remains dismal. The relative 1-year survival rate for pancreatic cancer is only $28 \%$, and the overall 5 -year survival is $7 \%$. Initial symptoms include weight loss, epigastric pain, jaundice etc. Unusual manifestations are suicidal tendencies, skin manifestations, migratory thrombophlebitis and others. Of all pancreatic cancers, $80 \%$ are adenocarcinomas of the ductal epithelium. Only $2 \%$ of tumors of the exocrine pancreas are benign. We here present a patient who presented to us with upper GI bleed and proved out to be pancreatic cancer.

\section{Case Report}

A 40 year old male, chronic alcoholic, presented to us with complaints of multiple episodes of melenic stools. Fifteen days back he started with passage of multiple foul smelling black tarry stools. Patient also gave history of easy fatigability over past two weeks. Intermittent epigastric pain mild to moderate in intensity and relieved by opioid analgesics and proton pump inhibitors was also present. There was no history of jaundice, vomiting, hematemesis, bleeding from any orifice or loose stools. On general physical examination patient was conscious and oriented. There was slight tachycardia and marked pallor. No stigmata of chronic liver disease were present. Respiratory and cardiovascular examinations were normal. Per abdomen liver was palpable $3 \mathrm{cms}$ below costal margin, firm and non-tender. No other abdominal mass was palpable. Baseline investigations revealed anaemia (Table 1).

Upper GI endoscopy was done that revealed bunch of fundal varices. Ultrasound abdomen showed Grade II fatty liver, $9 \mathrm{~mm}$ portal vein with no ascites. Pancreas was normal. A CECT abdomen was done that revealed pancreas showing mildly enhancing ill-defined mass lesion measuring $3.6 \mathrm{~cm} \times 3.8 \mathrm{~cm} \times 4.7 \mathrm{~cm}$ involving body and causing obliteration of splenic vein (Figures 1 and 2). Multiple gastric, peripancreatic and perisplenic varices were present. Liver, Portal vein and Spleen were normal. No significant mesenteric/retroperitoneal lymphadenopathy was present.

Patient underwent Exploratory Laparatomy with multiple Pancreatic Biopsies and devascularisation. Intraoperative findings included multilobulated mass lesion predominantly in body of pancreas, diffuse in extension with adhesions with lesser sac and peripancreatic planes (Figures 3 and 4).
Few nodes and minimal ascites were seen. Multiple fundal varices were also observed. Histopathology was pancreatic adenocarcinoma. Patient was referred to oncology department for further management. However patient declined further treatment.

\section{Discussion}

Pancreatic cancer is a very rare cause of upper gastrointestinal bleeding. Besides initial presentation of pancreatic malignancy as upper GI bleed is equally raren [1]. Lee et al. studied eight patients in whom major digestive hemorrhage was the first sign of a subsequently proven pancreatic malignancy. In seven out of the eight cases, direct tumor invasion into a contiguous portion of the GI tract was the cause of bleed [2]. Ohtsubo performed endoscopy in 75 patients with pancreatic cancer between 2003 and 2010. Among the 75 patients with pancreatic cancer, 56 gastrointestinal lesions were identified in 46 patients $(61 \%)$ during the clinical course as follows: gastroduodenal invasion (26\%), esophagogastric varices (18\%), radiation-induced gastroduodenal mucosal lesions (12\%), gastroduodenal ulcers (except radiation-induced ulcers) (10\%), portal hypertensive gastropathy (4\%), duodenal metastasis (1.3\%), and gastrointestinal bleeding from unknown primary site (1.3\%). Fifteen (27\%) lesions were accompanied by upper gastrointestinal bleeding. Another rare cause of upper GI bleed in pancreatic cancer is sinistral or left sided portal hypertension.

Left sided portal hypertension is a localised form of portal hypertension that occurs as a result of spelnic vein obstruction [3]. The pathophysiology of this condition was first described by Greenwald and Wasch. Splenic vein occlusion results in back pressure which is transmitted through its anastomoses with the short gastric and gastroepiploic veins and subsequently via the coronary vein into the portal system. This results in reversal of flow in these veins and the formation of gastric varices. Acute and chronic pancreatitis, pancreatic neoplasms, idiopathic splenic vein thrombosis and splenic vein injury

*Corresponding author: Waseem Raja Dar, MBBS MD, Department of Medicine Gastroenterology Division, Shere Kashmir Institute of Medical Sciences, Soura Jammu and Kashmir, India, Tel: +918222800676; E-mail: drwaseem.mw@gmail.com

Received December 19, 2015; Accepted January 14, 2016; Published January 21, 2016

Citation: Latief M, Dar WR, Qayoom O, Sofi N, Dar IA, et al. (2016) An Unusual Presentation of Pancreatic Cancer. J Gen Pract 4: 223. doi: 10.4172/23299126.1000223

Copyright: @ 2016 Latief M, et al. This is an open-access article distributed under the terms of the Creative Commons Attribution License, which permits unrestricted use, distribution, and reproduction in any medium, provided the original author and source are credited. 
Citation: Latief M, Dar WR, Qayoom O, Sofi N, Dar IA, et al. (2016) An Unusual Presentation of Pancreatic Cancer. J Gen Pract 4: 223. doi: 10.4172/2329-9126.1000223

\begin{tabular}{|c|c|c|c|c|}
\hline Parameter & Result & Parameter & Result & \multirow{8}{*}{\begin{tabular}{lc}
\multicolumn{2}{c}{ USG Abdomen; } \\
1. & Grade II \\
& fatty liver. \\
2. & Portal \\
& vein $9 \mathrm{~mm}$. \\
3. & Pancreas \\
& normal
\end{tabular}} \\
\hline $\mathrm{Hb}$ & $5.7 \mathrm{~g} \%$ & Urea & $2 \mathrm{mg} / \mathrm{dl}$ & \\
\hline TLC & $68300 / \mathrm{mm}^{3}$ & Creatinine & $1.05 \mathrm{mg} / \mathrm{dl}$ & \\
\hline DLC & $\begin{array}{c}\text { Neutros }=70 \% \\
\text { Lymphos }=21 \%\end{array}$ & Bilirubin & $0.27 \mathrm{mg} / \mathrm{dl}$ & \\
\hline PLT & $1.6 \mathrm{lacs} / \mathrm{mm}^{3}$ & ALT & $32 \mathrm{U} / \mathrm{L}$ & \\
\hline Chest Xray & Normal & ALP & $202 \mathrm{U} / \mathrm{L}$ & \\
\hline ECG & $\begin{array}{l}\text { Normal Sinus } \\
\text { Rhythm }\end{array}$ & Total Protein & $6.12 \mathrm{~g} / \mathrm{dl}$ & \\
\hline Coagulogram & Normal & Albumin & $3.15 \mathrm{~g} / \mathrm{dl}$ & \\
\hline
\end{tabular}

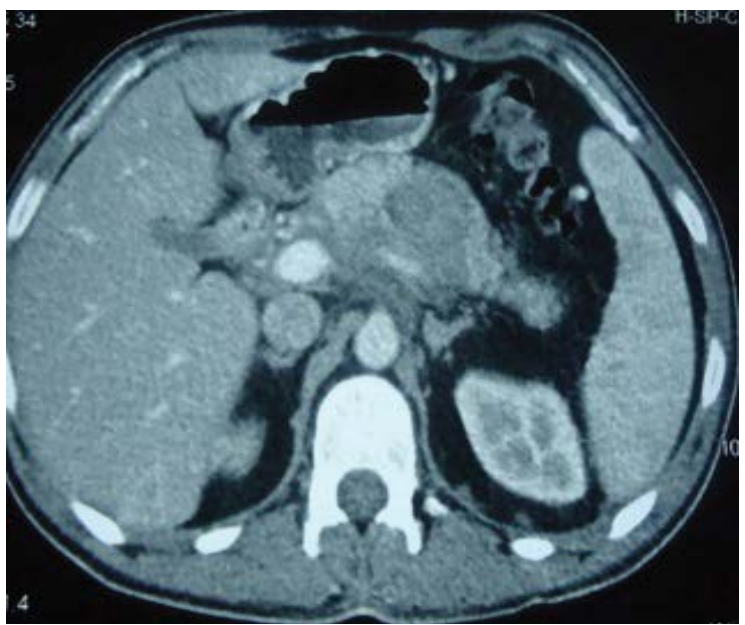

Figure 2: Fundal varices.

Table 1: Investigations

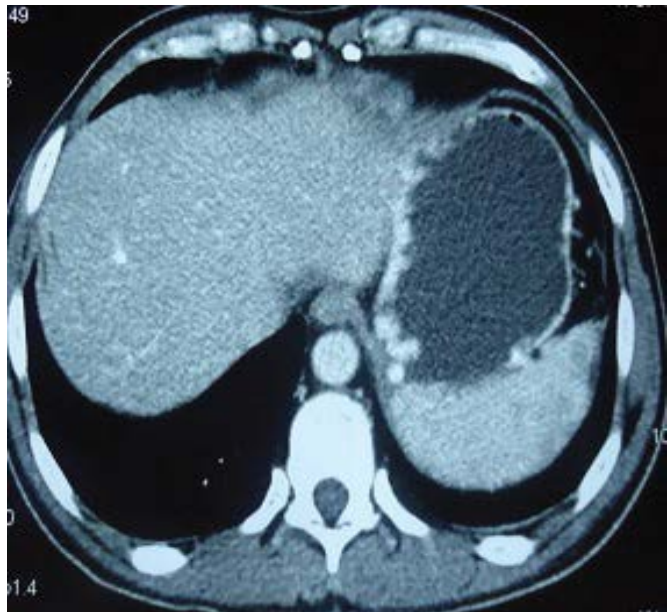

Figure 1: III-defined pancreatic mass.

are important causes of sinistral hypertension. Left-sided portal hypertension should be considered in the presence of gastrointestinal bleeding with normal liver function and unexplained splenomegaly [4].

Pancreatic disorders remain the major causes of sinistral portal hypertension. The splenic vein is susceptible in lesions of the pancreas due its close anatomical course along the superior pancreatic surface [5]. Thompson et al., described a case series of 4 patients with sinistral portal hypertension due to pancreatic pathology. Two of the four patients were of pancreatic neoplasms [6]. Thrainsdottir et al. reported a patient of Mucinous cystic neoplasm of pancreas leading to left-sided portal hypertension, causing bleeding from isolated gastric varices similar to our case.

Correction of the primary cause and splenectomy in case of massive hemorrhage remain the mainstay of the treatment. Treatment of asymptomatic varices remains unclear [7]. The advantages of laparoscopic over open splenectomy are well-known but in 2008 EAES guidelines on laparoscopic splenectomy, portal hypertension

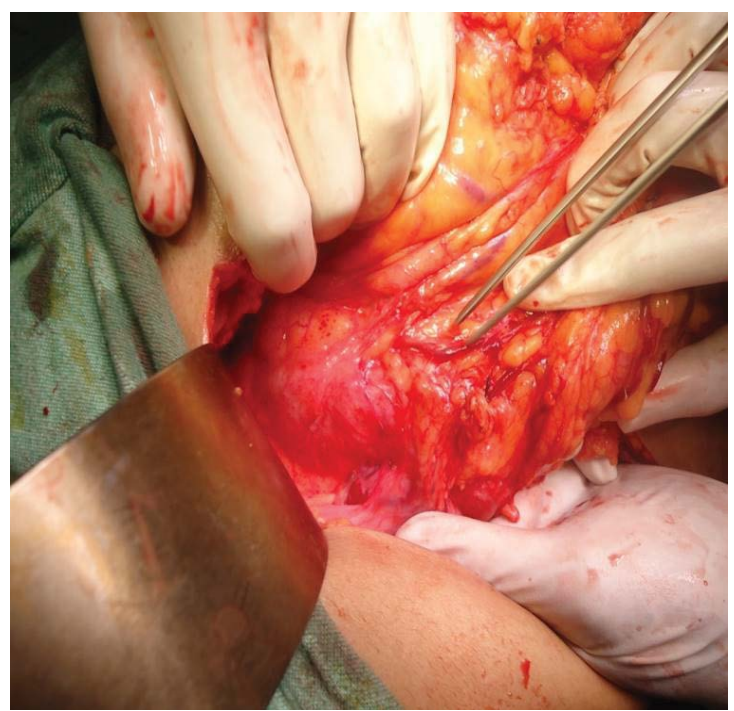

Figure 3: Multilobulated mass lesion involving pancreas.

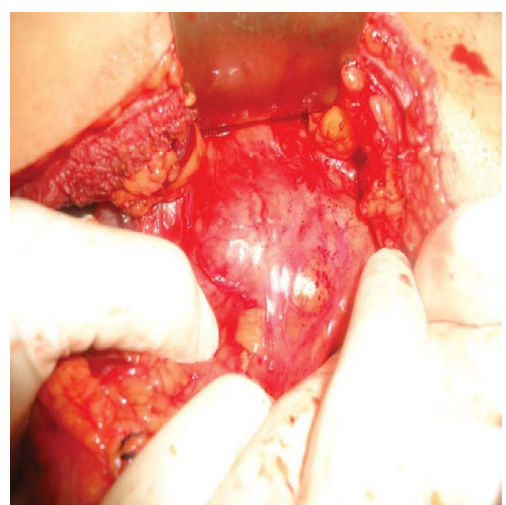

Figure 4: Multi lobulated mass lesion involving pancreas. 
Citation: Latief M, Dar WR, Qayoom O, Sofi N, Dar IA, et al. (2016) An Unusual Presentation of Pancreatic Cancer. J Gen Pract 4: 223. doi: 10.4172/2329-9126.1000223

Page 3 of 3

represents a contraindication to laparoscopy, given the higher risk of intra-operative hemorrhage. However left sided portal hypertension represents a very different anatomic setting from cirrhosis-related portal hypertension. Pre-operative splenic artery embolism can be used as a means to reduce the venous pressure at the splenic hilum and to allow a safer and easier dissection of the splenic vessels, which could be successfully accomplished by laparoscopy [8], Such an approach was used by Patrono et al. in a patient of chronic pancreatitis-related splenic vein thrombosis causing left-sided portal hypertension with gastric fundus varices and splenic cavernoma. Following splenic artery embolization (SAE), the case was successfully managed by laparoscopic splenectomy.

\section{Summary}

Upper GI bleed is an unusual presentation of pancreatic cancer. When a patient presents with isolated gastric varices with normal liver function tests, splenomegaly and normal extrahepatic portal vein, sinistral hypertension should be suspected. Pancreatic pathology is the major etiology. Correction of the underlying pathology and splenectomy remain the main treatment strategies. Prognosis depends upon the underlying condition.

\section{References}

1. Patty Lee, Donald Sutherland, Edward R (1994) Feller. Massive gastrointestinal bleeding as the initial manifestation of pancreatic carcinoma. International Journal of Pancreatology 15: 223-227.

2. Ohtsubo K, Watanabe H, Mouri H, Yamashita K, Yasumoto K, et al. (2012) Endoscopic findings of upper gastrointestinal lesions in patients with pancreatic cancer. JOP 13: 420-426

3. Greenwald HM, Wasch MG (1939) The roentgenologic demonstration of esophageal varices as a diagnostic aid in chronic thrombosis of the splenic vein. J Pediatr 14: 57-65.

4. Koklu S, Coban S, Yuksel O, Arhan M (2007) Left-sided portal hypertension Dig Dis Sci 52: 1141-1149.

5. Thompson RJ, Taylor MA, McKie LD, Diamond T (2006) Sinistral portal hypertension. The Ulster medical journal 75: 175-177.

6. Thrainsdottir H, Petursdottir V, Blöndal S, Bjornsson ES (2014) "Pancreatic Mass Leading to Left-Sided Portal Hypertension, Causing Bleeding from Isolated Gastric Varices," Case Reports in Gastrointestinal Medicine.

7. Habermalz B, Sauerland S, Decker G, Delaitre B, Gigot JF, et al. (2008) Laparoscopic splenectomy: the clinical practice guidelines of the European Association for Endoscopic Surgery (EAES). Surg Endosc 22: 821-848.

8. Patrono D, Benvenga R, Moro F, Rossato D, Romagnoli R, et al. (2014) Left-sided portal hypertension: Successful management by laparoscopic splenectomy following splenic artery embolization. International Journal of Surgery Case Reports 5: 652-655. 